\title{
Caminhos (in)sustentáveis: a rota de caminhada e peregrinação Passos dos Jesuítas-Anchieta, em São Paulo
}

\author{
(Un)sustainable paths: The routeof trekking andpilgrimage Passos dos \\ Jesuítas-Anchieta, São Paulo state
}

\author{
Patrícia Mariuzzo ${ }^{a}$ \\ Aline Vieira de Carvalhob
}

\begin{abstract}
${ }^{a}$ Pesquisadora do Laboratório Interdisciplinar do Patrimônio, Ambiente e Comunidades do Núcleo de Estudos e Pesquisas Ambientais da Unicamp (Lipac/Nepam), http://www.nepam.unicamp.br/lipac/nepam/.
\end{abstract}

${ }^{\mathrm{b}}$ Coordenadora do Núcleo de Estudos e Pesquisas Ambientais (Nepam), da Universidade Estadual de Campinas (Unicamp), pesquisadora do Laboratório Interdisciplinar do Patrimônio, Ambiente e Comunidades do Núcleo de Estudos e Pesquisas Ambientais da Unicamp (Lipac/Nepam).

Recebido em: 24/03/2017 I Aceito em: 12/06/2017

ARTIGO

\section{RESUMO}

Nesse artigo aliamos perspectivas da história ambiental, do turismo, da gestão pública para analisar as práticas turísticas na rota de caminhada e peregrinação Passos dos JesuítasAnchieta, no litoral do Estado de São Paulo, Brasil. Criada em 2011, Passos dos Jesuítas é uma rota pedestre com 370 quilômetros, entre as cidades de Peruíbe e Ubatuba. A metodologia se baseou em uma abordagem qualitativa, com opção pelo estudo de caso e pesquisa de campo. Analisamos os discursos oficiais produzidos pela Secretaria de Turismo do Estado de São Paulo, fizemos entrevistas com gestores das cidades envolvidas no projeto turístico e com os turistas/peregrinos que percorreram a rota, dentro de um recorte temporal de 2011 a 2014. Nosso ponto de partida foi a crença de que o patrimônio - seja ele cultural ou natural - é uma construção discursiva que tem efeitos concretos que podem ser vivenciados pelos indivíduos, sejam eles da comunidade local ou turistas. No caso em questão, a despeito dos discursos oficiais afirmarem que esse produto turístico é um programa de turismo sustentável, a não participação das comunidades locais na idealização e manutenção do produto comprometem essa pretensa sustentabilidade. Além disso, ao aderir uma visão tradicional de patrimônio, esse produto entrega um passado esvaziado de conflitos. Se há pouco espaços para as dúvidas acerca de sua sustentabilidade, porque modelos como esses continuam sendo adotados pelo poder público? Diante da perplexidade de algumas opções acerca do turismo, nesse texto, optamos por analisar o caso específico dos Passos dos Jesuítas-Anchieta para expandir a reflexão para um quadro 
mais geral. Esperamos, dessa forma, contribuir ativamente para os debates acerca do Turismo Sustentável e Desenvolvimento que não se iniciam ou se encerram em 2017.

Palavras-chave: Caminhada. Peregrinação. Turismo sustentável. Patrimônio. Comunidades.

\begin{abstract}
In this article, we combine perspectives on environmental history, tourism, and public management to analyze tourism practices on the route of treckking and pilgrimage Passos dos Jesuítas-Anchieta on the coast of the State of São Paulo, Brazil. Created in 2011, by the state government, it is a pedestrian route with 370 kilometers, between the cities of Peruíbe and Ubatuba. The methodology was based on a qualitative approach, with the option of case study and field research. We analyzed the official speeches produced by the Tourism Secretariat of the State of São Paulo, we also conducted interviews with managers of the cities involved in the tourism project and with the tourists / pilgrims who traveled the route, within a time frame from 2011 to 2014. Our starting point was the belief that heritage - be it cultural or natural - is a discursive construction with concrete effects can be experienced by individuals, be they of the local community or tourists. In this case, although the official discourses affirm that the tourism product Passos dos Jesuítas-Anchieta is an example of sustainable tourism, the non-participation of the local communities in the idealization and maintenance of the product compromise this presumed sustainability. In addition, by adhering to a traditional view of heritage, this product delivers a past emptied of conflicts. If there is little room for doubts about its sustainability, why such models are still being adopted by the public power? Faced with the perplexity of some options about tourism, in this text, we chose to analyze the specific case of the Passos dos Jesuitas to expand the reflection to a more general picture. We hope, therefore, to actively contribute to the debates on Sustainable Tourism and Development.
\end{abstract}

Keywords: Treckking. Pilgrimage. Sustainable tourism. Heritage. Communities.

\title{
1 INTRODUÇÃO
}

No final do ano de 2016, a Assembleia Geral da Organização das Nações Unidas (ONU) aprovou a determinação do ano de 2017 como tempo de celebração do Turismo Sustentável para o Desenvolvimento. A proposta da ONU é reunir experiências, diálogos e transformações catapultadas dos níveis locais para a esfera internacional, com a finalidade de promover mudanças significativas nas práticas turísticas e na vida cotidiana daqueles que se relacionam direta e indiretamente com essas práticas.É importante destacar que, com essa declaração, há um expressivo reconhecimento por parte da ONU de que o turismo é transformador, e, nesse contexto, pode ser instrumentoportador de uma energia capaz de construir uma sociedade mais justa, plural e inclusiva. 
$\mathrm{Na}$ declaração do ano de 2017 como Ano Internacional do Turismo Sustentável', as potencialidades e as complexidades do turismo são organizadasem cinco principais eixos de debates: 1. Crescimento econômico sustentável e inclusivo; 2. Inclusão social, emprego e redução da pobreza; 3. Eficiência dos recursos, proteção do ambiente e alterações climáticas; 4. Valores culturais, diversidade e patrimônio; e, 5. Compreensão mútua, paz e segurança.Desta forma, é bastante claro que há muito espaço para debates e ações não apenas vindos de diferentes localidades, mas, também de diferentes áreas do conhecimento. Nesse artigo, aliamos perspectivas da história ambiental, do turismo e da gestão pública para analisar a rota de caminhada e peregrinação Passos dos Jesuítas-Anchieta, em São Paulo buscando entender como a história do Brasil, natureza, memórias e identidades locais foram apropriadas em um roteiro turístico no litoral paulista, região tradicionalmente associada ao turismo de sol e praia.

O objetivo desse artigo é compreender o processo de criação da rota Passos dos Jesuítas e, nesse contexto, identificar como se deu a participação dos atores envolvidos/impactados pelo projeto turístico. Nossa proposta foi realizar uma análise qualitativa dos discursos oficiais produzidos pela Secretaria de Turismo do Estado de São Paulo com o intuito de desvelar visões sobre a natureza do litoral paulista e suas implicações. Não foi nosso objetivo fazer uma avaliação desse produto turístico ou estabelecer generalizações, mas, por meio de um estudo em profundidade, construir uma explicação válida para o caso analisado.

Por meio de uma abordagem qualitativa analisamos os textos produzidos pela Secretaria de Turismo do Estado de São Paulo (Setur): relatórios, memoriais, materiais institucionais (como o mapa da rota, guia do caminhante), textos publicados no portal do programa Caminha São Paulo e produzidos pela assessoria de imprensa da Secretaria e assessoria do governo do Estado para divulgação do projeto.Procurando ampliar nosso corpus de pesquisa, incluímos em nossa metodologia entrevistas semiestruturadas individuais com gestores de turismo da Secretaria de Turismo e de algumas das cidades envolvidas no programa. $O$ principal objetivo das entrevistas era investigar como ocorreu a implantação do programa Caminha São Paulo e da rota Passos dos Jesuítas - Anchieta e de que forma os municípios foram envolvidos nesse processo. No contexto das 13 cidades,

\footnotetext{
${ }^{1}$ Documento disponível em: http://www2.unwto.org/tourism4development2017 Acesso: 19/03/2017.
} 
optamos por fazer entrevistas individuais e gravadas com os gestores das cidades de Peruíbe, Ubatuba e Itanhaém. Nossa crença na representatividade desse recorte em relação ao conjunto de gestores de turismo do conjunto de municípios participantes da rota deveu-se à alguns fatores: em primeiro lugar porque Peruíbe e Ubatuba é onde estão o marco zero e final da rota respectivamente, conferindo a esses lugares um papel específico nessa narrativa; Itanhaém foi a única cidade que recebeu uma ação de divulgação da rota no período contemplado pela nossa pesquisa. Em segundo lugar, essa escolha deveu-se ao fato de termos tido acesso ao Diagnóstico Operacional Rota Passo dos Jesuítas - Anchieta Programa Caminha São Paulo Relatório de Pesquisa Qualitativa, uma pesquisa encomendada pela Setur, em 2012, onde constam depoimentos dos gestores de turismo das 13 cidades participantes da rota (NC PESQUISAS, 2012).

Não há dúvidas para aqueles que já praticaram a rota ou são afetados por ela que os caminhos, nesse caso, não são nada sustentáveis.Mas, se há pouco espaços para as dúvidas acerca de sua sustentabilidade, porque modelos como esses continuam sendo adotados pelo poder público? Diante da perplexidade de algumas opções acerca do turismo, nesse texto, optamos por analisar o caso específico dos Passos dos Jesuítas-Anchieta para expandir a reflexão para um quadro mais geral. Esperamos, dessa forma, contribuir ativamente para os debates, que não se iniciam ou se enceram em 2017, acerca do Turismo Sustentável e Desenvolvimento.

\section{OS CAMINHOS PARA CRIAR UM CAMINHO}

Em setembro de 2011, a Secretaria de Turismo do Estado de São Paulo (Setur) lançou a rota pedestre Passos dos Jesuítas - Anchieta $^{2}$, um roteiro para caminhada e peregrinação no litoral paulista. Com 370 quilômetros, o trajeto passa por 13 cidades: Peruíbe, Itanhaém, Mongaguá, Praia Grande, São Vicente, Santos, Guarujá, Bertioga, Cubatão, São Sebastião, Ilhabela, Caraguatatuba e Ubatuba (figura 1) e compõe a rota Passos dos Jesuítas, um roteiro que reproduziria os caminhos percorridos pelos padres jesuítas nesta região na segunda metade do século XVI, sobretudo por José de Anchieta.

\footnotetext{
${ }^{2} \mathrm{http}: / /$ www.passosdosjesuitas.com.br/publico/
}

Ciência e Sustentabilidade - CeS / Juazeiro do Norte, v. 3, n. 1, p. 8-32, jan/jun 2017 
Figura 1: Cidades por onde passa a rota Passos dos Jesuítas.

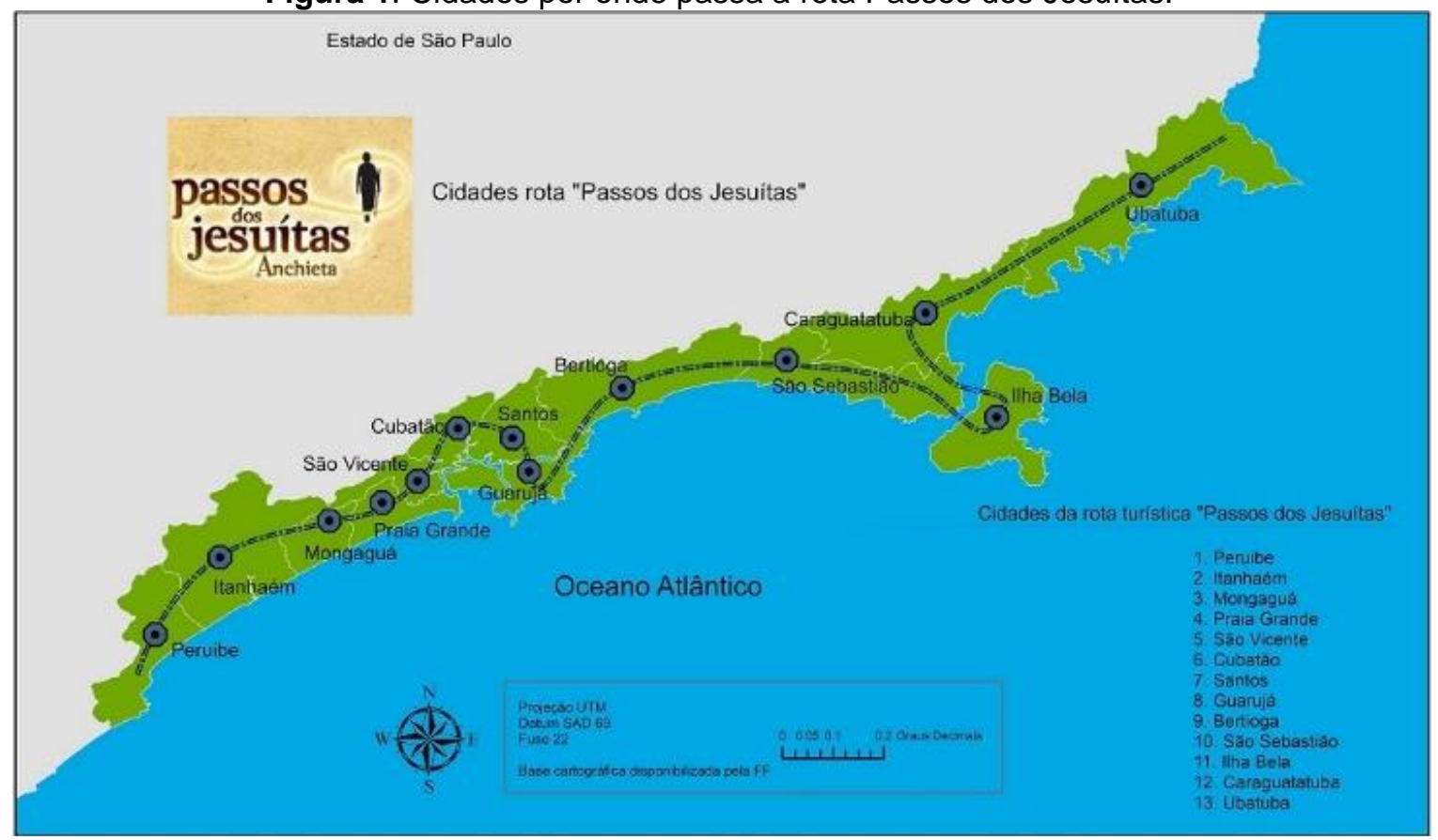

Elaboração Patricia Mariuzzo, 2016.

A rota faz parte do Caminha São Paulo ${ }^{3}$, um programa inspirado no Caminho de Santiago, na Espanha, que, segundo a Setur, tem o objetivo de promover o turismo nas cidades paulistas a partir da criação de roteiros peregrinos baseados no trajeto utilizado por personagens históricos e religiosos. Além da rota Passos dos Jesuítas, outras três foram implantadas: a Rota Franciscana (Frei Galvão), a Rota dos Bandeirantes (Fernão Dias) e a Rota da Luz (Dutra). Todas podem ser realizadas sem a contratação de guias especializados e os turistas/peregrinos contam com uma infraestrutura que inclui placas de sinalização, portais na internet com informações sobre as cidades, monitoramento eletrônico dos participantes e certificado de conclusão dos roteiros.

Nos discursos elaborados para divulgar esse destino turístico, a Setur destaca a possibilidade de o turista fazer uma redescoberta das riquezas naturais, históricas, culturais, religiosas e monumentais de cidades do litoral paulista. Destino tradicionalmente ligado ao turismo de sol e praia, o litoral paulista, marcado pela vulnerabilidade de seus ecossistemas e pela especificidade do conter $40 \%$ do território da região protegido por Unidades de Conservação (UCs), adquirem novos sentidos nesses discursos oficiais. Natureza e patrimônio arquitetônico, então,

${ }^{3} \mathrm{http}: / /$ www.caminhasaopaulo.com.br/publico/

Ciência e Sustentabilidade - CeS / Juazeiro do Norte, v. 3, n. 1, p. 8-32, jan/jun 2017 
servem de cenário para novas modalidades turísticas, nesse caso para a prática de caminhadas de longo curso, que possibilitaria uma viagem de "contemplação, história e fé" (SÃO PAULO, 2011, p. 49)

O embrião da rota Passos dos Jesuítas - Anchieta é um projeto turístico criado em 2002 na cidade de Peruíbe. Segundo informações da Secretaria de Turismo dessa cidade, a ideia era criar um produto turístico similar ao "Passos de Anchieta", no Espírito Santo. O "Passos de Anchieta" foi criado em 1998, pela Associação Brasileira dos Amigos dos Passos de Anchieta (Abapa) ${ }^{4}$. Trata-se de um percurso de 100 quilômetros entre Vitória, capital do estado do Espírito Santo e o Santuário Nacional São José de Anchieta, construído entre os séculos 16 e 17 e localizado na antiga Aldeia de Reritiba, fundada pelo padre José de Anchieta e onde ele faleceu, hoje centro histórico da cidade de Anchieta, no Espírito Santo. O roteiro é sinalizado com placas. De acordo com os organizadores, esta seria a primeira rota de peregrinação cristã do Brasil. A caminhada pode ser feita em qualquer época do ano por meio de pacotes turísticos comercializados pela Associação. Ao final, o turista recebe um certificado emitido pelo Santuário Nacional São José de Anchieta. A rota "Passos de Anchieta" recebe cerca de 200 caminhantes por ano. No entanto, o maior afluxo de turistas ocorre no feriado de Corpus Christi. Em 2015, quatro mil turistas se inscreveram para fazer a caminhada.

Inspirados nesse projeto, representantes dos departamentos de turismo das prefeituras de Peruíbe e de Itanhaém, da comunidade indígena Piaçaguera, da Associação Comercial de Itanhaém e ainda de duas agências de turismo, idealizaram o roteiro "Caminhos de Anchieta: Trilha do Abarebebê": uma caminhada de 25 quilômetros, com duração aproximada de seis horas e meia, acompanhada por monitores, reconstituindo as andanças dos primeiros colonizadores na região e especialmente dos jesuítas, os padres José de Anchieta e Leonardo Nunes. O local de saída era o centro histórico de Itanhaém, percorrendo alguns marcos históricos em Itanhaém, a orla do litoral, pela comunidade indígena Piaçaguera (onde haveria apresentação de danças e venda de artesanato), até as Ruínas do Abarebebê, patrimônio estadual arqueológico, que reúne vestígios de uma capela jesuíta.

\footnotetext{
${ }^{4}$ Fonte: ABAPA, disponível em http://www.abapa.org.br/. Consultado em 30/01/2016.
}

Ciência e Sustentabilidade - CeS / Juazeiro do Norte, v. 3, n. 1, p. 8-32, jan/jun 2017 
O passeio era comercializado ${ }^{5}$ no formato de pacotes turísticos pelas agências envolvidas e oferecido uma vez por mês. Esse projeto contou também com o apoio da Associação Pró-Canonização de Anchieta (Canan), ligada à Companhia de Jesus e que à época trabalhava pela canonização do (então) Beato José de Anchieta, e da Secretaria de Turismo do Estado, por meio de sua Delegacia Regional.

A partir de 2003 há tentativas de ampliar o projeto, especialmente por iniciativa da Canan, que contava com parcerias de outras instituições, entre elas, o Conselho de Desenvolvimento da Baixada Santista (Condesb), a Agência Metropolitana da Baixada Santista (AGEM) e a Secretaria de Turismo do Estado. Segundo Fleck e Kasper, que estudam as representações do missionário José de Anchieta no Brasil, alguns dos lugares de memória e monumentos instituídos ou erigidos em torno da figura de Anchieta estão diretamente vinculados ao processo de sua canonização, um movimento que recebeu a atenção de associações de religiosos e leigos empenhados em atender as exigências para que o beato se tornasse santo (FLECK\&KASPER, 2010, p. 155). Esse é o caso da Canan.

Desde o século XVII, a Companhia de Jesus trabalhava pela canonização de José de Anchieta. Após sua morte (aos 63 anos, no Espírito Santo), algumas relíquias foram enviadas para Roma para dar início ao processo de beatificação que começou oficialmente em 1624. Desde então, o processo sofreu várias interrupções. Em meados da década de 1960, a causa foi assumida por membros da alta hierarquia da Igreja Católica no Brasil, por autoridades governamentais e civis e por leigos católicos. Em 1965 é instituído no Brasil o "Dia de Anchieta", associando a figura de Anchieta a um exemplo de santidade e correção, imagem utilizada pelo governo militar para reafirmar a importância da família, da religião e da moral, auxiliando esse governo a solidificar os laços com uma importante parcela da população brasileira que foi às ruas protestar contra a direção esquerdista do governo de João Goulart (FLECK, 2007, p. 233). A beatificação do padre, etapa que antecede a canonização, aconteceu em 1980, logo após a visita do Papa João Paulo Il ao Brasil e só foi possível após a eliminação da exigência de comprovação de

\footnotetext{
${ }^{5}$ Duas agências de turismo de Peruíbe - Na trilha da Jureia e PierBox - ainda oferecem esse roteiro turístico.
}

Ciência e Sustentabilidade - CeS / Juazeiro do Norte, v. 3, n. 1, p. 8-32, jan/jun 2017 
milagres, previsto pelo Código Civil Canônico. Nesses casos a beatificação é concedida pelo conjunto da obra (FLECK\&KASPER, 2010, p. 168).

Em 2002, foi criada a Associação Pró-canonização de Anchieta (Canan) com sede na cidade de São Paulo. Seu objetivo era promover e divulgar a devoção popular ao beato Anchieta, visando a realização de um milagre, condição necessária para a santificação (FLECK\&KASPER, 2010). Foi como parte desse esforço que a Canan idealizou, em conjunto com as instituições apontadas acima, a rota de peregrinação religiosa que foi chamada de "Caminhos de Anchieta".

A estrutura do projeto baseava-se em três roteiros de peregrinação demarcados com placas: o primeiro a partir de Ubatuba, no Litoral Norte, outro com início na Baixada Santista e o terceiro começando na cidade de São Paulo. Além das placas de sinalização, em parceria com as prefeituras, seriam construídas as "Praças de Anchieta", pontos de apoio para o peregrino com banheiros e locais de descanso. O ponto final dos três roteiros seria um "santuário ecológico" dedicado a José de Anchieta em Praia Grande, em um terreno de 26 mil metros quadrados, doado pela prefeitura. Essa proposta estava ancorada no ideal de que a presença de Anchieta na região estava associada ao meio ambiente natural regional, especialmente o relacionado à Mata Atlântica e ao seu trabalho com os índios (AGEM, CANAN, s/d, p. 10).

Cabe lembrar, entretanto, que essa ideia de um meio ambiente natural ou natureza edênica com os quais o padre jesuíta se associava harmoniosamente, não é a única que prevalece nos escritos de Anchieta, ao contrário, trata-se de uma relação perpassada por conflitos. Conforme mostram as cartas e relatos do padre, o mundo natural, ao mesmo tempo que era criação de Deus, era também um tipo de inferno verde, morada do demônio e de homens decadentes: os indígenas não convertidos. Anchieta colocava em lados opostos uma sociedade harmoniosa construída pelo colonizador português e pela igreja e a natureza dissonante (ALVIN\&COSTA, 2005, p. 12). Estas contradições, entretanto, desaparecem dos discursos turísticos elaborados para promover essas rotas e o resultado um tipo de apagamento de especificidades históricas.

Ao longo da elaboração do projeto da Canan, também foi solicitado às prefeituras das cidades da Baixada Santista que elencassem "atrativos complementares pertinentes" à memória anchietana. A ideia era que o caminho de 
peregrinação que seria criado fosse resultado da interligação destes pontos com os pontos turísticos comprovados, "procurando, sempre que possível, manter-se uma sobreposição das rotas ao real caminho percorrido pelo beato" (AGEM, CANAN, s/d: 20). Boa parte dos locais selecionados neste projeto coincide com os lugares indicados no guia do caminhante da rota Passos dos Jesuítas-Anchieta como visitas complementares ao trajeto.

Em 2007, a Companhia de Jesus decidiu encerrar as atividades da Canan, provavelmente devido aos altos custos envolvidos na manutenção da sua sede, na cidade de São Paulo. Com isso, todos os projetos e iniciativas promovidos pela Associação foram transferidos para a sede da Companhia, na mesma cidade (FLECK\&KASPER, 2010, p. 164). Ainda de acordo com esses autores, outra razão para a desmobilização da causa pela canonização seria para evitar conflitos com os religiosos tidos como mais progressistas, críticos do projeto colonial ibérico e das estratégias de evangelização adotadas pelo jesuíta José de Anchieta e outros missionários junto às populações indígenas.

Apenas em 2015 uma nova iniciativa de caráter religioso em homenagem à José de Anchieta surge no litoral paulista: a peregrinação "Caminhando com Anchieta”. Organizada pela Diocese de Caraguatatuba, com apoio da Companhia Municipal de Turismo de Ubatuba. Não há participação da Companhia de Jesus. A peregrinação religiosa foi resultado do projeto de animação devocional após a canonização de José de Anchieta, que aconteceu em abril de 2014. De acordo com os organizadores, a peregrinação é um evento anual de incentivo a devoção a São José de Anchieta cujo objetivo é o fortalecimento da espiritualidade dos participantes através da caminhada, atividade que, segundo os organizadores ofereceria a possibilidade de uma experiência espiritual através do exercício físico e da contemplação das belezas naturais do Litoral Norte.

O percurso tem início em na Igreja Matriz de São Sebastião, passa por Ilhabela e Caraguatatuba, terminando na Igreja Matriz, em Ubatuba, em um trajeto de aproximadamente 80 quilômetros que aproveita em parte, a sinalização da rota Passos dos Jesuítas-Anchieta. Seguindo a tradição das peregrinações tradicionais, os peregrinos fazem pausas em paróquias ao longo do caminho para se alimentar, descansar, pernoitar e fazer orações. No primeiro ano quem foi organizada, em 
2015, 60 pessoas participaram da caminhada. Em 2016, o número atingiu 80 peregrinos.

A despeito do projeto da Setur contemplar o turismo religioso, acreditamos que esse movimento da igreja local de organizar peregrinações em torno da figura de José de Anchieta, é resultado de novas leituras da narrativa proposta pelos discursos oficiais. Tanto os organizadores, quanto os peregrinos que participam dessas caminhadas ignoram todo o aporte tecnológico do projeto, fazendo uso apenas da sinalização. Sem pretender um aprofundamento no entendimento desses novos sentidos, nos arriscamos a afirmar que, a partir dessa iniciativa, novas construções narrativas da rota Passos dos Jesuítas são elaboradas.

\section{DE UM PROJETO DE CANONIZAÇÃO PARA UM PROJETO TURÍSTICO}

Em 2011, com objetivo de colocar em prática as diretrizes do Programa de Regionalização do Turismo, a então recém-criada Secretaria de Turismo do Estado de São Paulo, retoma o projeto de criar roteiros de caminhada no litoral inspirados em José de Anchieta. Nesse momento, no entanto, a característica de uma peregrinação estritamente religiosa é amenizada. Com isso, nos discursos oficiais sobre o projeto além da palavra peregrino surge o termo caminhante. A figura de José de Anchieta é esvaziada de seu conteúdo religioso e ele passa a ser mostrado como personagem central no processo de colonização do Brasil. A motivação religiosa é substituída pelo apelo do turismo sustentável, com ênfase no patrimônio histórico e cultural e nas belezas naturais do litoral.

Qual seria o contexto político de onde emergiram essas decisões? Que atores, instituições e ideias compõem o quadro que fazem surgir o programa turístico Caminha São Paulo e a rota pedestre Passos dos Jesuítas - Anchieta?

A Secretaria de Turismo do Estado de São Paulo foi criada no dia $1^{\circ}$ de janeiro de 2011, pelo decreto 56.635/2011. Antes disso as ações relacionadas ao turismo no estado de São Paulo eram de responsabilidade da Coordenadoria do Turismo, ligada à Secretaria de Esportes, Lazer e Turismo (SELT). Não foi a primeira vez, entretanto, que o Estado de São Paulo contou com uma secretaria específica

para tratar dos assuntos relacionados ao turismo. Analisando o processo de institucionalização do turismo no Governo do Estado de São Paulo da década de 
1950 até os anos 2000, as turismólogas Raquel Brocchi e Karina Solha (2008), identificaram inúmeras transformações na estrutura e, principalmente, na nomenclatura deste órgão, o que, segundo elas, "revela pouca prioridade e fragilidade do setor, uma vez que dificulta a realização de projetos consistentes e de longo prazo". A esta fragilidade se associa o fato de que as ações desses órgãos seguirem, de maneira geral, as diretrizes nacionais para o turismo, ao invés de elaborar uma política estadual de turismo que contemple as especificidades dos municípios paulistas (BROCCHI; SOLHA, 2008, p. 252).

O programa Caminha São Paulo busca colocar em prática as diretrizes do Programa de Regionalização do Turismo, lançado pelo Ministério do Turismo brasileiro em 2004. A regionalização é um dos componentes do "Plano Nacional de Turismo: Diretrizes, Metas e Programas 2003-2007" Elaborado pelo Ministério do Turismo, o PNT 2003-2007 tinha como objetivo aumentar a oferta de produtos turísticos brasileiros e de oportunidades de desenvolvimento socioeconômico por meio da ação conjunta das três esferas do governo (municipal, estadual e federal), da sociedade, iniciativa privada e as organizações não governamentais. Para operacionalizar o PNT em todo território nacional foram criados Fóruns Estaduais, que deveriam funcionar como um canal de comunicação com o governo federal. No ano seguinte ao lançamento do PNT, o Ministério do Turismo cria um programa específico para estruturar e administrar o turismo do país de forma descentralizada e por regiões, o "Programa de regionalização do turismo. Roteiros do Brasil: Diretrizes políticas" (BRASIL, MTur, 2004).

$\mathrm{Na}$ opinião dos pesquisadores da área de turismo Aline Henz e Alexandre dos Anjos, da Universidade Estadual do Oeste do Paraná (Unioeste) e da Universidade do Vale do Itajaí (Univale), a introdução da gestão descentralizada do turismo no Brasil segue um modelo mundial de planejamento focado na distribuição de competências e união de forças por meio de roteiros, circuitos e polos turísticos (ANJOS\& HENZ, 2012, p.02).Para esses pesquisadores, o PNMT não foi capaz de conciliar os interesses de partidos municipais, estaduais e federais, "a falta de informações mais específicas para gerenciar a atividade e o fato de que municípios isolados de grandes centros não conseguiam aplicar o plano, foram motivos visíveis que causaram descontinuidade do PNMT" (ibidem, p. 03). Entretanto, ele teve êxito no sentido de fortalecer a crença de que gestão descentralizada seria o caminho 
para consolidar o turismo como instrumento de fortalecimento da economia. Dez anos depois da criação do PNMT, o foco do Programa de Regionalização do Turismo, como proposta de política pública para a gestão das atividades relacionadas ao turismo no Brasil, não é mais o município isolado, mas a região.

De acordo com o discurso do Ministério do Turismo, a proposta partiu da observação de um fenômeno que já vinha ocorrendo em vários estados brasileiros: a criação e oferta de roteiros turísticos que extrapolavam as fronteiras dos municípios e até mesmo dos estados. "... constatou-se que a integração de municípios em uma região turística seria a melhor forma de incluir no processo de desenvolvimento os municípios que sempre ficavam à margem da implementação das políticas públicas" (BRASIL, MTur: 2007, p. 19).

Conforme as diretrizes operacionais do Programa de Regionalização do Turismo, no processo de regionalização é fundamental 0 envolvimento representantes de todas as instâncias: poder público, empresários, sociedade civil, instituições de ensino e terceiro setor. Especialmente em relação aos municípios, questão que nos interessa, a partir das premissas apontadas no Programa de Regionalização, supõe-se que eles participem do planejamento regional das atividades turísticas, agregando valores e serviços por meio de suas peculiaridades.

Dois conceitos principais norteiam o Programa do Ministério do Turismo. 0 primeiro é o conceito de território, visto como espaço e lugar de interação do homem com o ambiente (BRASIL, MTur, 2004, p.11). A adoção desse conceito supõe novas formas de organização social que vão além das divisões administrativas e geográficas e procura destacar características, valores e particularidades distintivos de uma região. Além disso, "o ordenamento territorial, articulado nesses novos moldes e convencionado a partir dos interesses coletivos da região, deve apresentar-se como sustentável e emancipador, ou seja, deve promover a inclusão econômica, social e cultural" (BRASIL, MTur, 2007, p. 26).

O segundo conceito adotado no Programa é o de arranjos produtivos locais (APLs). Tradicionalmente aplicado nos estudos das áreas de administração e economia, o termo APL designa uma região ou município que tem como uma de suas principais características a presença marcante de um setor industrial específico. Sendo o turismo um setor caracterizado por colocar à disposição do turista diversas atividades ao mesmo tempo, para uma região ser considerada um 
APL (ou cluster) de turismo ela deve apresentar um número expressivo de empresas envolvidas com a atividade turística como restaurantes, hotéis, agências e operadoras de turismo, empresas de transporte e ainda organizações públicas e privadas de apoio que ofereçam infraestruturas básicas como estradas, saneamento e hospitais para atender os visitantes (BRASIL, MTur, 2007b, p. 1-9).Esses dois conceitos serviriam como guias para o reconhecimento de atributos e características presentes em determinadas regiões, ultrapassando as fronteiras geográficas dos municípios, capazes de gerar produtos e serviços complementares para a diversificação da oferta turística, traduzindo-se, assim, em oportunidades de negócios e de desenvolvimento humano (BRASIL, MTur, 2004, p. 09).

De acordo com o professor de turismo da Escola de Comunicações da Universidade de São Paulo (ECA/USP), Mário Carlos Beni, o incentivo à diversificação por parte das políticas públicas segue uma tendência nesse setor que busca destacar as vantagens competitivas de uma região e não suas vantagens comparativas. Essas se baseiam na existência de recursos que os competidores não têm ou têm em menor medida como atrativos turísticos únicos, mão de obra barata e experiência acumulada. Já as vantagens competitivas são criadas, "levando para o mercado novas formas de competir e novas maneiras de fazer as coisas" (BENI, 1999, p. 15). Ora, a proposta do programa Caminha São Paulo vai exatamente nessa direção, propondo uma nova forma de conhecer conjuntos de municípios - a pé - que, supostamente, teriam atrativos e serviços complementares e ainda uma herança comum, as marcas deixadas por José de Anchieta.

Entretanto, a Setur contradiz as premissas do programa de regionalização ao dispensar a participação das comunidades envolvidas, da iniciativa privada e mesmo das estâncias públicas da esfera municipal. O distanciamento em relação às propostas iniciais tanto do projeto "Caminhos de Anchieta: trilha do Abarebebê", elaborado pelas prefeituras de Peruíbe e Itanhaém, quanto do roteiro religioso "Caminhos de Anchieta", significou também um afastamento das prefeituras, das comunidades e da iniciativa privada, que estavam presentes no embrião do projeto turístico, em 2002.

No caso das prefeituras, esse distanciamento foi atestado pelo diagnóstico da rota Passos dos Jesuítas, encomendado pela própria Secretaria do Turismo em 2012 e executado por uma empresa de consultoria. O documento aponta a falta de 
integração entre governo estadual e municípios como uma barreira para a consolidação do projeto. Os gestores municipais entrevistados para a elaboração desse documento percebem que o projeto turístico é inovador no sentido de incrementar o turismo regional e, principalmente, pelo seu potencial de atrair turistas fora de temporada (um turista diferenciado, com alto poder aquisitivo e com grande bagagem cultural). No entanto, como esse tipo de atividade é uma novidade, com pouca tradição no Brasil, ela demanda ampla divulgação. Isso, segundo esses gestores, depende de ações integradas entre as prefeituras e a esfera estadual (NC PESQUISAS, 2012, p. 16-17).

A maioria dos representantes da área de turismo das instâncias municipais (secretários, diretores, coordenadores etc.) apontou ainda que, como o programa foi implantado de cima para baixo, sem participação ou consulta às prefeituras, não houve estímulo para um envolvimento maior. Segundo eles, seria necessário manter as secretarias municipais atualizadas em relação ao desenvolvimento dos trabalhos, pesquisas realizadas, quantidade de caminhantes, informações sobre o público-alvo, além de realizar reuniões periódicas de integração e planejamento junto aos municípios (ibidem, p. 18-19).

Funari e Carvalho apontaram a educação patrimonial como uma alternativa ao distanciamento entre a sociedade e seus diversos patrimônios. De acordo com eles, a educação patrimonial possibilita diálogos por meio dos quais acontece uma conexão entre a vida cotidiana das pessoas e os patrimônios. Acreditamos que a partir de um projeto de educação patrimonial sobre essa rota de caminhada, envolvendo prefeituras e comunidades, poderiam emergir reflexões acerca da herança jesuíta na região, bem como da presença de comunidades indígenas, quilombolas e caiçaras. Tais reflexões, se inseridas no projeto, poderiam resultar em patrimônios multifacetados e, por isso, mais ricos para a comunidade e para os turistas. No entanto, as tentativas de aproximação com comunidade foram tímidas e descontínuas, gerando frustração e falta de identificação com esse produto turístico.

Após o lançamento da rota Passos dos Jesuítas, em 2011, aconteceram alguns eventos de divulgação organizados em parcerias da Secretaria de Turismo com prefeituras locais. Em 2011 foi montado na cidade de Ubatuba o espetáculo teatral "Encenação da Paz de Iperoig", sobre a participação de José de Anchieta nas negociações de paz entre os tamoios e os portugueses no século XVI. A montagem 
foi coordenada pelo Instituto Paz de Iperoig, criado exclusivamente para esse fim. Por meio de uma parceria com a Secretaria de Educação de Ubatuba, o Instituto recrutou artistas locais, incluindo alunos, pais e professores em um total de 300 participantes (ZISKIND, 2011). O espetáculo aconteceu no dia 28 de outubro na Praia do Cruzeiro. Na ocasião um grupo com 22 caminhantes concluíram um trecho da rota, chegando momentos antes do início do espetáculo. No ano seguinte, aconteceu apenas uma exposição de fotos do espetáculo de 2011 . No entanto, a partir de 2013 não houve mais apresentações. De acordo com representantes do Instituto Paz de Iperoig, sem o apoio da prefeitura de Ubatuba e da Secretaria de Turismo do Estado, a instituição não foi capaz de articular parcerias e levantar recursos para a montagem do espetáculo.

Em junho de 2014, logo após a canonização de José de Anchieta, em parceria com a Prefeitura de Itanhaém e duas paróquias dessa cidade, aconteceu a Semana Anchieta, coincidindo com as comemorações do Dia de Anchieta. A programação do evento contou com uma missa campal, celebrando a canonização de Anchieta, uma caminhada de três quilômetros na rota Passos dos Jesuítas e uma exposição de fotografias de trechos da rota, ambos para divulgar o projeto turístico. Em Itanhaém, a canonização do padre motivou a criação de um projeto de lei (Lei № 3.928, de 2 de junho de 2014) que proclamou Anchieta co-padroeiro da cidade, juntamente com Nossa Senhora da Conceição. Segundo o Secretário de Turismo de Itanhaém, a Semana de Anchieta foi o primeiro evento em que houve uma parceria efetiva da Secretaria de Turismo do Estado com a prefeitura, com discussão prévia do projeto e envolvimento das paróquias locais. Cerca de 150 pessoas das cidades de Itanhaém, Peruíbe e Santos participaram das atividades.

O secretário adjunto de turismo da cidade de Peruíbe também apontou a falta de integração do Estado com as instâncias locais como um dos pontos fracos do projeto: Para ele, a comunidade indígena Piaçaguera, "uma das coisas mais interessantes no caminho", precisaria ser envolvida. De fato, essa comunidade, que participou da primeira iniciativa de se criar uma rota de peregrinação no litoral de São Paulo, o roteiro Passos de Anchieta, Trilhas do Abarebebê, não foi incluída no projeto Passos dos Jesuítas. Indagada sobre isso, a Secretaria de Turismo nos informou que convidou as comunidades indígenas para oficinas de sensibilização via prefeituras, para que elas conhecessem os projetos, mas que apenas duas 
aceitaram participar: a comunidade Itaóca, em Mongaguá, e a Rio Silveira, em Bertioga/São Sebastião. No entanto, informações que obtivemos em entrevistas que fizemos com secretários de turismo de algumas cidades por onde passa a rota, contradizem essa afirmação. Em Peruíbe, por exemplo, segundo seu secretário adjunto, não houve nenhuma tentativa de aproximação com a comunidade indígena: "Eu não me lembro de nenhum treinamento, apenas do lançamento, que foi feito com um grande evento", declarou.

Conforme nos ensinou o ex-diretor do Conselho Internacional dos Museus (ICOM), Hugues de Varine, projetos que intencionem gerar desenvolvimento social e econômico e que envolvam questões patrimoniais devem ser feitos o mais próximo possível dos criadores e dos detentores desse patrimônio. "Não se pode ter desenvolvimento sem a participação efetiva, ativa e consciente da comunidade que detém esse patrimônio". (VARINE, 2012, p. 21).

Nos discursos oficiais a respeito desse roteiro turístico, apenas três comunidades indígenas - Itaóca, Aguapeú (ambas na cidade de Mongaguá) e Rio Silveira (na divisa de Bertioga com São Sebastião) - são mencionadas, nenhuma como passagem obrigatória. Nesses discursos elas são apenas sugeridas como locais a serem visitados pelo turista. No entanto, existem outras sete comunidades indígenas nas cidades onde passa a rota Passos dos Jesuítas - Anchieta.

No discurso de lançamento da rota, o governador destacou: "Nós temos aqui a história. (...) Aqui está presente a história do Brasil”. O texto do mapa do caminhante também enfatiza essa "redescoberta" como mostramos no trecho destacado abaixo. Como em um parque temático, a "história do Brasil" é oferecida como atrativo turístico. No entanto, os caminhos propostos para o turista percorrer "repousam em desejáveis e intencionais geografias da mente", conforme afirma o geógrafo norte-americano David Lowenthal (2002, p. 12). Segundo ele, "como os parques temáticos no presente, a paisagem do passado é, em geral, um artifício, uma invenção, uma construção, uma ilusão. Ele é menos o que ele era realmente do que o que deveria ter sido" (LOWENTHAL, 2002, p.14). Na construção narrativa oferecida ao turista as comunidades indígenas são excluídas da "história do Brasil" que se pretende contar, elas tornam-se completamente invisíveis. Trata-se de uma catequização sem indígenas já que não há espaço para eles no presente. 
A desvalorização dos indígenas mostrou-se como um requisito para a concretização do enredo narrativo. Nesta história os indígenas não têm um papel relevante porque a narrativa foi construída de modo a obscurecer seu papel. Ora, se uma das propostas da rota é criar condições para que o turista conheça a história da colonização e do povoamento do Estado de São Paulo, por que os indígenas são excluídos?

Como apontou Luchiari (1997, p. 54), a ocupação indígena das terras brasileiras, anterior à colonização não deixou muitas marcas na paisagem local, mas transmitiu fortes legados culturais, entre eles muitas trilhas e caminhos. Trilhas que certamente eram utilizadas por José de Anchieta, uma herança que não é mencionada em um projeto turístico que pretende recuperar exatamente isso, caminhos antigos do Brasil.

A Setur adere ao uma visão tradicional de patrimônio, que exclui as compreensões do patrimônio localizadas fora ou em oposição a esse discurso autorizado do patrimônio. Assim, como apontou Smith, a herança que não provém das elites, que são subnacionais ou não ocidentais são ignoradas e descartadas, definidas como de interesse de minorias. "A possibilidade de compreensões diversas, multiculturais ou transacionais do passado e do presente frequentemente é impedida pelo discurso autorizado do patrimônio" (SMITH, 2011, p. 45).

O Estado, que investiu recursos público neste projeto turístico, parece ignorar a complexidade da história colonial (caracterizada por negociações e violência entre índios e europeus), a existência de uma pluralidade de religiosidade em nosso país, e, finalmente, as comunidades que fizeram e fazem parte dessa história. O resultado é um passado esvaziado de conflitos, "um fantasma inofensivo" (CARVALHO, 2010, p. 190). Apagam-se cinco séculos de transformações, simplificando cenários e atores. Como afirma Cronon, "a capacidade de inclusão é uma virtude porque seguramente uma história é melhor quando incorpora muitas vozes e eventos diferentes para refletir a diversidade de experiências humanas passadas" (CRONON, 2002, p. 59).

Em consonância com as reflexões sobre usos do passado, do historiador da Universidade Federal de São Paulo (Unifesp), Glaydson José da Silva, partirmos da premissa de que o saber sobre o passado, sua escrita e suas leituras são poderes e geram poderes (SILVA, 2005: XV). Com objetivo de forjar identidades, os grupos 
sociais evocam determinadas memórias, imagens, personagens, lugares, ligando-os à uma pretensa ancestralidade que justificaria sua perpetuação na vida nacional. É o que vemos em relação à figura de José de Anchieta. No entanto, "essas memórias da nação visam, de certo modo, uma espécie de controle do passado (e, consequentemente), do presente" (SILVA, 2005, p. 72). E esse processo envolve uma gestão de memórias "que significa, antes de tudo, controlar a materialidade em que a memória se expressa (das relíquias aos monumentos, aos arquivos, símbolos, rituais, datas, comemorações...)" (SEIXAS, 2001, p. 42).

No contexto desse projeto do governo do estado, neste roteiro entre Peruíbe até Ubatuba, um trajeto específico foi escolhido, além disso, foram selecionados sítios para visitação, lugares de memória (NORA, 1993) que buscam destacar uma suposta vocação histórica, cultural e religiosa e, assim, costurar novos significados para o litoral dentro da experiência do caminhar.

No conjunto de elementos escolhidos para passagem e para visitação na rota Passos dos Jesuítas, destacam-se igrejas, capelas e outros marcos da catequização jesuítica no litoral, como nos exemplos que destacamos na figura a seguir.

Figura 2: Cruzeiro Quinhentista em Cubatão/SP.

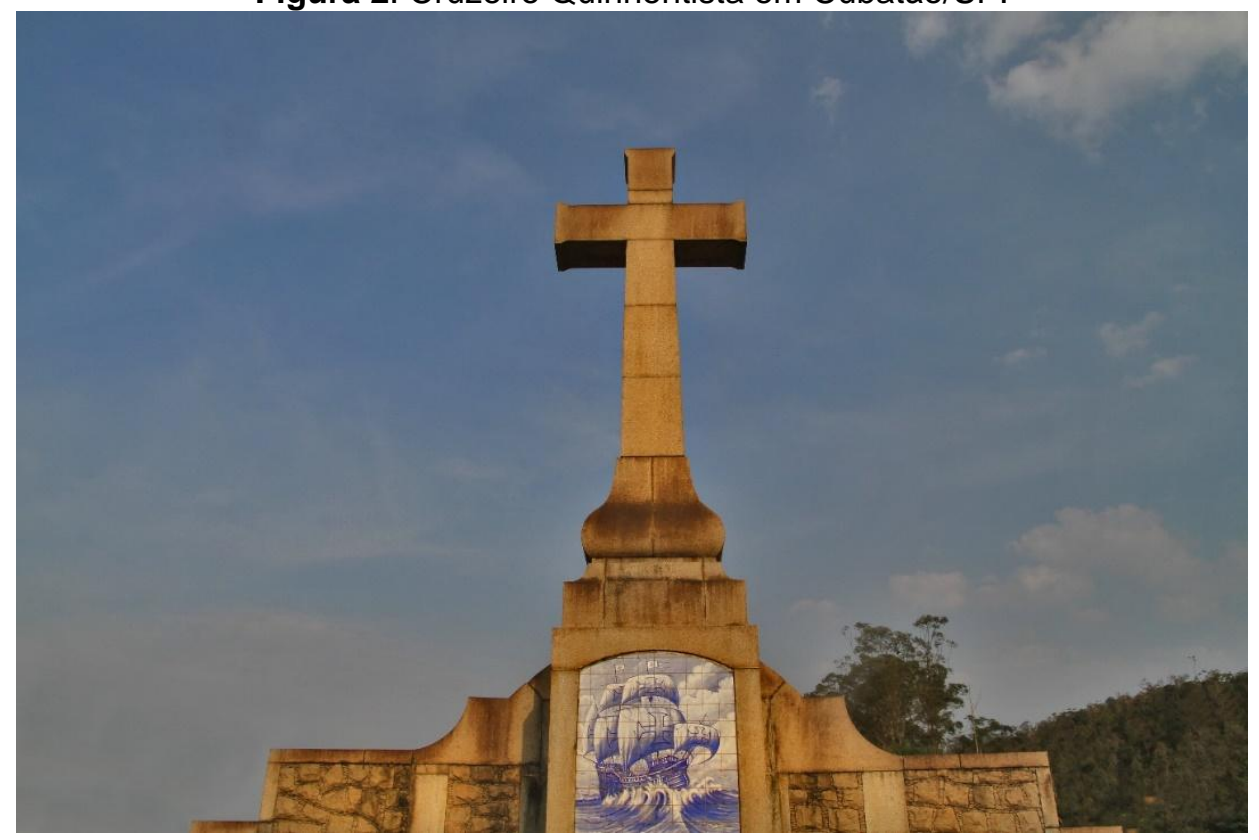

Fonte: Setur, 2014.

No entanto, estas escolhas levam em conta apenas o catequizador e não o catequizado, em um tipo de história católica, colonial e branca. Como afirmam 
Funari e Carvalho, os monumentos históricos são portadores de mensagens e, por sua natureza como cultura material, são usados pelos atores sociais para produzir significados (FUNARI \& CARVALHO, 2011, p. 07). No Brasil, frequentemente, as políticas patrimoniais perpetuam percepções culturais colonialistas (CARVALHO, 2010, p. 21 e CARVALHO \& SOUZA, 2015, p. 18). Dignos de serem lembrados no presente e no futuro, as igrejas e outros edifícios católicos materializam a presença europeia no território brasileiro, para consolidar traços em comum entre o Brasil e o velho continente. Outras expressões religiosas, como as expressões da religiosidade indígena, não são mencionadas. Partilhando das ideias das historiadoras Aline Carvalho e Luciana Souza, apontar essas ausências não significa limitar essas discussões à oposição simplista colonizado x colonizador, mas abrir possibilidades para outras representações no jogo político que resulta na valorização dos patrimônios. Como alertou Hannah Arendt no prefácio do livro Entre o passado e o futuro (1979), na operação que nega a diversidade do patrimônio há o perigo do apagamento de memórias e isso, em termos de realidade política, pode resultar na incapacidade de projetar o futuro.

\section{CONSIDERAÇÕES FINAIS}

A incorporação do conceito de sustentabilidade no turismo, em suas diversas dimensões (ambiental, social, econômica, cultural, política, filosófica etc.), serve como um guia para muitas entidades, especialmente na década de 1980, quando ONGs e órgãos de proteção à natureza, cientes da necessidade de novos modos para a conservação, passam a aceitar o turismo como a menos impactante das alternativas econômicas nos ambientes naturais protegidos por lei (POLES; RABINOCI, 2010, p.14). No plano internacional, ocorre a sistematização de planos e documentos para servirem de referência para a prática desse "novo" turismo. A "Agenda 21 para a Indústria de Viagens e Turismo: em direção ao Desenvolvimento Ambientalmente Sustentável" (Agenda 21 for theTravelandTourismlndustry: TowardsEnvironmentallySustainableDevelopment ${ }^{6}$ ), é um deles, elaborado pela Organização Mundial do Turismo (UNWTO), pelo Conselho Mundial de Viagens e

\footnotetext{
${ }^{6}$ Fonte: World Travel Tourism Council, World Tourism Organization, Earth Council. Agenda 21 for the Travel \& Tourism Industry: Towards environmentally Sustainable Development, London, 1998.
} 
Turismo (WTTC) e pelo Conselho da Terra (ECA).É nessa conjuntura que se expandem e se consolidam novas modalidades de turismo entre elas o agroturismo, turismo de aventura e o ecoturismo, na qual se insere rotas de caminhada como a Passos dos Jesuítas ${ }^{7}$.De acordo com esse documento, a atividade turística sustentável é a que atende as necessidades dos turistas e das regiões receptoras, ao mesmo tempo em que protege e cria oportunidades para o futuro. Um produto turístico sustentável deve, portanto, operar em harmonia com o meio ambiente, a comunidade e a cultura locais para que esses elementos se tornem beneficiários e não vítimas do desenvolvimento turístico (WTTC, 1998, p. 30).

No Brasil, é principalmente a partir dos anos 1990 que os órgãos públicos passam a desenvolver ações para o turismo sustentável e para o ecoturismo. Em 1994, foi elaborado o documento "Diretrizes para uma Política Nacional de Ecoturismo" (BRASIL, 1994). Este documento serviu de base para a elaboração das "Diretrizes para a política estadual de ecoturismo" (1997), criada pela Secretaria de Estado do Meio Ambiente (SMA) em parceria com o Núcleo de Estudos e Pesquisas Ambientais (NEPAM), da Universidade Estadual de Campinas, Unicamp.

Não existe uma definição consensual para o termo ecoturismo. Conforme explicam Regiane Faco e ZysmanNeiman, muitas vezes são usados termos como "turismo de natureza", "turismo verde", "turismo ecológico" ou ainda "turismo responsável", para se referir a essa atividade. O ecoturismo, segundo esses turismólogos, "deve garantir que a interação entre o ser humano e a natureza desencadeie, por meio da relação vivencial, a reflexão sobre a exploração dos recursos e a compreensão de que os mesmos devem ser usados de forma sustentável" (FACO\&NEIMAN, 2010, p. 45). Para a Sociedade Internacional de Ecoturismo (TIES), esta atividade turística estaria relacionada a viagens para áreas naturais, visando preservar o meio ambiente e promover o bem-estar da população local $\left.\right|^{8}$. De forma semelhante, nas "Diretrizes para a política estadual de ecoturismo",

\footnotetext{
${ }^{7}$ A Secretaria de Turismo inclui as caminhadas e a rota Passos dos Jesuítas-Anchieta entre as atividades do segmento do ecoturismo que podem ser realizadas no Estado de São Paulo. Elas são definidas como: expedições (a pé ou de bike) por trilhas geralmente levam até atrativos naturais como praias, cachoeiras, cavernas e topos de montanhas. Podem ser praticadas por pessoas de qualquer idade, levando-se em consideração inclinação e relevo do terreno e a distância a ser percorrida. Seu principal objetivo é a contemplação de paisagens que, dependendo do local escolhido, envolve a observação de animais em seu habitat natural (SÃO PAULO, Secretaria de Turismo, s/d).

${ }^{8}$ Fonte: The International Ecotourism Society (TIES). Disponível em: http://www.ecotourism.org/whatis-ecotourism. Acesso em 12/06/2017.
}

Ciência e Sustentabilidade - CeS / Juazeiro do Norte, v. 3, n. 1, p. 8-32, jan/jun 2017 
ecoturismo é o segmento turístico que utiliza o patrimônio natural e culturalde forma sustentável, incentiva sua conservação e busca a formação de uma consciência ambientalista, promovendo o bem-estar das populações (SÃO PAULO, Secretaria do Meio Ambiente, 1997, p. 06).Independentemente da definição que se adote, três características devem estar presentes: garantia de conservação ambiental, educação ambiental e benefícios para as comunidades receptoras (FACO\&NEIMAN, 2010, p. 45).

Ao implantar essa rota turística, para ser percorrida a pé, a Secretaria de Turismo incentiva um modelo de turismo sustentável, de menor impacto. Entretanto, acreditamos que o ecoturismo pressupõe mais do que contato com a natureza. Como afirmarmos antes, essas atividades tem o potencial de gerar educação ambiental e benefícios para as comunidades envolvidas, objetivos que a rota Passos dos Jesuítas ainda não foi capaz de concretizar. Como lembram Ribeiro e Barros (1997), "sob esse manto da retórica da sustentabilidade" podem se esconder projetos conservadores, que retomam conceitos bastante tradicionais sobre patrimônio e que não levam em conta visões de grupos minoritários e das comunidades locais.Os discursos oficiais que embasam essa iniciativa tentam inaugurar um novo olhar para as cidades do litoral do Estado, um olhar que aponta para outras características dessas cidades, além de suas praias, que busca valorizar seu patrimônio histórico e cultural.Entretanto, um projeto turístico que não envolve a comunidade pode ser realmente sustentável?

$\mathrm{Na}$ narrativa histórica desse roteiro turístico atores fundamentais, como indígenas e caiçaras, são esquecidos, tornam-se invisíveis. Mesmo a escolha de um padre jesuíta para ser consagrado como herói indica a valorização de representações tradicionais do patrimônio nacional e regional. Como alertou Cronon, "nenhuma narração baseada em um único personagem central poderia ser politicamente inocente". O resultado são ocultamentos, ora das comunidades indígenas, ora das mulheres, grupos étnicos, classes baixas e qualquer outra comunidade diferente daquela representada por esse protagonista (CRONON, 2002, p. 42).

Da mesma forma que acontece no contexto internacional, no Brasil, estamos assistindo o investimento de enormes fundos públicos na criação de cenários que representam momentos históricos da história nacional e sobre a natureza 
(ALFONSO, 2012: 56). O objetivo destes investimentos é promover o turismo em diferentes áreas do país. Frequentemente o patrimônio tem sido usado como plataforma desses projetos (idem, p. 158), (SILBERMAN, 2016, p. 50). Infelizmente, não é incomum que as diversas entidades do poder público procurem inspiração em outros países, optando por fazer uma "transposição" destas experiências (ALFONSO, 2012, p. 158); (CARNEIRO, 2004, p. 72), (STEIL; CARNEIRO, 2008, p. 107).

Um exemplo dessas "adaptações' é rota Passos dos Jesuítas-Anchieta. Idealizada como uma rota de caminhada e peregrinação nos moldes da rota de Santiago de Compostela, a rota destaca um patrimônio cultural católico e a Mata Atlântica como patrimônio natural. A ideia é oferecer ao turista a algo próximo da "experiência de contemplação" dos jesuítas que viveram no Brasil no século XVI. Compreendendo o patrimônio como um conjunto de bens que faz referências a identidades e memórias de diferentes grupos sociais, perguntamos: é possível preservar um patrimônio por parte de pessoas que não se identificam com ele? Como consolidar um produto turístico em uma comunidade, mobilizando um passado e um patrimônio que lhe é estranho? (FUNARI \& CARVALHO, 2011, p. 11).

Nossa análise evidenciou que esses discursos oficiais, impostos de cima para baixo, com pouca ou nenhuma participação das comunidades locais, tornam-se frágeis e vulneráveis a mudanças de caráter político e mesmo pessoal, ou seja, não se traduzem em projetos sustentáveis, que, conforme apontamos anteriormente, são aqueles capazes de continuar além de seus promotores iniciais ou das circunstâncias de seu lançamento (VARINE, 2012, p. 38). Tratam-se de fórmulas políticas recorrentes que geram fracassos no sentido da sustentabilidade, fortalecendo a hipótese de que, sem o envolvimento local, o patrimônio não adquire sentido plural e efetivo.

\section{REFERÊNCIAS}

AGEM, CANAN. Caminhos de Anchieta: projeto. Santos: AGEM, s/d., 63 p.

ALFONSO, L.P. Arqueologia e turismo: sustentabilidade e inclusão social. 2012. Tese (Programa de Pós-Graduação em Arqueologia, Museu de Arqueologia e Etnologia). Universidade de São Paulo. São Paulo. 
ALVIM, D. M.; COSTA, R. Anchieta e as metamorfoses do imaginário medieval na América portuguesa. Revista Ágora, Vitória, n. 1, 2005, p. 1-19.

ANJOS, F.A.; HENZ, A.P. Planejamento do turismo no Brasil entre 2003 e 2007. IX Seminário da Associação Nacional de Pesquisa e Pós-Graduação em Turismo.Universidade Anhembi-Morumbi, São Paulo, 2012, p. 1-12.

BENI, M. C. Política e estratégia do desenvolvimento regional: planejamento integrado e sustentável do turismo.Turismo em Análise, São Paulo, maio 1999, 10 (1):7-17.

BRASIL. Ministério da Indústria, do Comércio e do Turismo/Ministério do Meio Ambiente, Recursos Hídricos e da Amazônia Legal. Diretrizes para uma política nacional de ecoturismo. Brasília, 1994. 48p.

BRASIL, Ministério do Turismo. Programa de Regionalização do Turismo: roteiros do Brasil: diretrizes políticas. Brasília, Ministério do Turismo. 2004.

Plano Nacional de Turismo: uma viagem de inclusão - 2007/2010. Brasília: 2007, 43 p.

BROCCHI, R. G.; SOLHA, K. T. Institucionalização do turismo no poder público estadual: a experiência de São Paulo. Turismo em análise, São Paulo, v. 19, n.2, ago.2008, p. 241-254.

CARNEIRO, S.M.C.S. Novas peregrinações brasileiras e suas interfaces com o turismo. Ciências Sociais e Religião, Porto Alegre, ano 6, nํ6, out 2004, p. 71-100.

CARVALHO, A. V., SOUZA L. C. Leituras acerca das políticas patrimoniais no Litoral Norte de São Paulo, Brasil. Geografia Ensino \& Pesquisa, Santa Maria (RS), v. 19, n. especial, 2015, p. 17-24.

CARVALHO, A. V. de. Entre ilhas e correntes: a criação do ambiente em Angra dos Reis e Paraty, Brasil. São Paulo: Annablume, 2010.

CRONON. W. Un lugar para relatos: naturaleza, historia y narrativa. In: Repensando la naturaleza. PALÁCIO, G.; ULLOA, A. (Orgs.). Colombia: Universidad Nacional de Colombia, 2002, p. 29-66. 
FACO, R.A., Neiman, Z. A natureza do ecoturismo: conceitos e segmentação". In ZYSMAN, N., RABINOVICI, A. (Orgs,). Turismo e meio Ambiente no Brasil. Barueri: Manole, SP, 2010, p. 43-62.

FLECK, E.C.D. Salvaguardando o princípio da moralidade e a integridade da nação: a apropriação de Anchieta pelo regime militar. História Unisinos, v. 11, no 2 , maio/ago. 2007, p. 278-281.

FLECK, E. C. D.; KASPER, R. Os lugares e os caminhos que celebram um beato: peregrinando pela causa da canonização de José de Anchieta. História, Franca (SP), v. 29, n. 1, 2010, p. 149-169.

FUNARI, P.P., CARVALHO, A.V. Patrimônio e diversidade: algumas questões para reflexão. In FUNARI, P.P., CARVALHO, A.V. (Orgs.) Patrimônio cultural, diversidade e comunidades. Campinas: IFCH Unicamp, 2011.

LOWENTHAL, D. The past as a theme park. In YOUNG, T e RILEY, R. (Orgs.). Theme park landscapes: antecedents and variants. Washington, DC: Dumbarton Oaks Press, 2002. p. 11-23.

LUCHIARI, M.T.D.P. Turismo e cultura caiçara no Litoral Norte paulista. In:

LUCHIARI, M. T. D.P. (Org.), Turismo e meio Ambiente, Vol. II, Textos Didáticos, IFCH/Unicamp, no 1(2), dez 1997, p. 53-82.

NC PESQUISAS. Diagnóstico operacional Rota Passos dos Jesuítas-Anchieta. Programa Caminha São Paulo. Relatório de pesquisa qualitativa.São Paulo: NC Pesquisas, ago. 2012, 31 p.

NORA, P. Entre história e memória: a problemática dos lugares. Projeto História. Revista do Programa de Estudos Pós-Graduados em História e do Departamento de História da PUC-SP, São Paulo, v. 10, 1993, p. 7-28.

POLES, G., Rabinoci, A. O ambientalismo, o turismo e os dilemas do desenvolvimento sustentável. In ZYSMAN, N., RABINOVICI, A. (Orgs.). A. Turismo e meio Ambiente no Brasil. Barueri: Manole, SP, 2010. p. 01-24.

SÃO PAULO, Secretaria de Turismo, Caminha São Paulo. Mapa da rota Passos dos Jesuítas-Anchieta. São Paulo: Secretária de Turismo, s/d.

Ecoturismo e turismo de aventura no Estado de São Paulo. São

Paulo: Secretaria de Turismo, s/d. 
Caminha São Paulo, Guia do Caminhante Passos dos Jesuítas-

Anchieta. São Paulo: Secretaria de Turismo, 2011, 49 p.

SÃO PAULO, Secretaria de Meio Ambiente, Coordenadoria de Educação Ambiental. Diretrizes para uma política estadual de ecoturismo. São Paulo, SP: SMA/CEAM, 1997. 25 p.

SEIXAS, J. A. de. Percursos de memória em terras de história: problemáticas atuais. In: BRESCIANI, S.; NAXARA, M. Memória e (re) sentimento: indagações sobre uma questão sensível. Campinas: Editora da Unicamp, 2001, p. 37-58.

SILBERMAN, N. A.; CARVALHO, A.; FUNARI, P.P. Desafios para o patrimônio mundial: em busca de novas práticas. Jundiaí: Paco Editorial, 2016, 102 p.

SILVA, G. J. da. Antiguidade, arqueologia e a França de Vichy: usos do passado. 2005.Tese (Instituto de Filosofia e Ciências Humanas). Universidade Estadual de Campinas, Campinas.

SMITH, L. El 'espejo patrimonial': ilusión narcisista o reflexiones múltiples?

Antípoda, Rev. Antrop. Arqueol. Bogotá, no 12, enero-junio, 2011, p. 39-65.

STEIL, C.A.; CARNEIRO, S.S. Peregrinação, turismo e nova era: caminhos de Santiago de Compostela no Brasil. Religião e Sociedade, Rio de janeiro, 28(1), 2008, p. 105-124.

VARINE, H. As raízes do futuro: o patrimônio a serviço do desenvolvimento local. Porto Alegre: Medianiz, 2012, $255 \mathrm{p}$.

WORLD TRAVEL TOURISM COUNCIL, World Tourism Organization, Earth Council. Agenda 21 for the travel \&tourism Industry: towards environmentally sustainable development, London, 1998,78 p.

ZISKIND, R. Ubatuba comemora 374 anos e recebe etapa final do Passos dos Jesuítas. São Paulo, Secretaria de Turismo, Caminha São Paulo. São Paulo, 28 out. 2011. 